NASA/TM-2001-211123

\title{
Performance of High-Speed PWM Control Chips at Cryogenic Temperatures
}

Malik E. Elbuluk

University of Akron, Akron, Ohio

Scott Gerber

ZIN Technology, Brook Park, Ohio

Ahmad Hammoud

QSS Group, Inc., Brook Park, Ohio

Richard Patterson and Eric Overton

Glenn Research Center, Cleveland, Ohio

Prepared for the

2001 Industry Applications Society Annual Meeting

sponsored by the Institute of Electrical and Electronics Engineers

Chicago, Illinois, September 30-October 5, 2001

National Aeronautics and

Space Administration

Glenn Research Center 


\section{Acknowledgments}

This work was supported by the NASA Glenn Research Center, Contract NAS3-00145, GESS Task 0020, and by JPL's NASA Electronic Parts and Packaging Program (NEPP).

This report contains preliminary findings, subject to revision as analysis proceeds.

Available from

NASA Center for Aerospace Information 7121 Standard Drive

National Technical Information Service 5285 Port Royal Road Springfield, VA 22100 


\section{Performance of High-Speed PWM Control Chips at Cryogenic Temperatures}

\author{
Malik E. Elbuluk \\ University of Akron \\ Akron, Ohio 44325 \\ Ahmad Hammoud \\ QSS Group. Inc. \\ Brook Park, Ohio 44142
}

\author{
Scott Gerber \\ ZIN Technology \\ Brook Park. Ohio 44142 \\ Richard Patterson and Eric Overton \\ National Aeronautics and Space Administration \\ Glenn Research Center \\ Cleveland, Ohio 44135
}

\begin{abstract}
Planetary exploration missions and deep space probes require electronics capable of low temperature operation. Such electronics will not only improve circuit performance and reliability, but also increase system efficiency, and reduce development and launch costs. DC/DC converters are an essential part of most aerospace power management distribution systems (PMAD). Therefore, DC/DC converters that can operate at cryogenic temperatures are crucial for space missions where low temperatures are encountered. An important component of a DC/DC converter is the pulse width modulation (PWM) chip that provides the control to the converter main switches.

In the process of designing low temperature DC/DC converters, experimental investigations were performed to evaluate the performance of a number of high-speed PWM chips as a function of temperature in the range of $25^{\circ} \mathrm{C}$ to $-190^{\circ} \mathrm{C}$. These integrated circuit (IC) chips ranged in their electrical characteristics, modes of control, packaging options, and applications. This paper presents and discusses the experimental procedures along with the experimental data obtained on the investigated chips.
\end{abstract}

\section{INTRODUCTION}

Future space missions, such as outer planetary exploration and deep space probes, require electrical power management systems that operate reliably and efficiently in very low temperature environments. For example, inter-planetary probe launched to explore the rings of Saturn would experience an average temperature of about $-183^{\circ} \mathrm{C}$.

Presently, spacecraft operating in the cold environment of deep space carry a large number of radioisotope heating units (RHU) to maintain temperature for the on-board electronics at approximately $20^{\circ} \mathrm{C} \mathrm{[1].} \mathrm{This} \mathrm{is} \mathrm{not} \mathrm{an} \mathrm{ideal}$ solution because the RHUs are always producing heat, even when the spacecraft is already too hot, thus requiring an active thermal control system for the spacecraft. In addition, they are very expensive and require elaborate containment structures. Electronics capable of operation at cryogenic temperatures will not only tolerate the hostile environment of deep space but also reduce system size and weight by eliminating radioisotope heating units and associated structures; thereby reducing system development and launch costs, improving reliability and increasing energy densities.

\section{POWER EleCtronics AT CRYOGENIC TEMPERATURES}

Power electronic circuits designed for operation at low temperature are expected to result in more efficient systems than those at room temperature. This improvement results from better electronic, electrical, and thermal properties of materials at low temperatures [2,3]. In particular, the performance of certain semiconductor devices improves with decreasing temperature down to liquid nitrogen temperature $\left(-196^{\circ} \mathrm{C}\right)[3,4]$. At low temperatures, majority carrier devices demonstrate reduced leakage current and reduced latch-up susceptibility. In addition, these devices show higher speed resulting from increased carrier mobility and saturation velocity [3-5]. An example is the power MOSFET that has lower conduction losses at low temperature due to the reduction in the drain-to-source resistance $R_{D S(o n)}$ resulting from increased carrier mobility $[4,6,7]$.

The Low Temperature Electronics Program at the NASA Glenn Research Center focuses on research and development of electrical components and systems suitable for applications in deep space missions [8]. Research is being conducted on devices and systems for use down to cryogenic temperatures. Some of the components that are being characterized include semiconductor switching devices, resistors, magnetics, and capacitors [9-11]. A number of commercial-off-the-shelf modular, low power DC/DC converters, with specifications that might fit the requirements of specific future space missions, have been tested. These converters, which ranged in electrical power from $8 \mathrm{~W}$ to $13 \mathrm{~W}$ and output voltage from $3.3 \mathrm{~V}$ to $12 \mathrm{~V}$, were characterized in terms of their performance as a function of temperature in the range of $20^{\circ} \mathrm{C}$ to $-190^{\circ} \mathrm{C}$ [12-14].

Efforts are in progress to build modular DC/DC converters with low temperature capabilities. The converters will be designed or modified to operate from room temperature to $-196{ }^{\circ} \mathrm{C}$ using commercially available or newly developed components such as CMOS-type 
devices and MOSFET switches. PWM IC chips will be used to implement the closed-loop control of the converters.

In this work, a preliminary evaluation of the performance of four high-speed PWM chips has been conducted as a function of temperature in the range of $25{ }^{\circ} \mathrm{C}$ to $-190^{\circ} \mathrm{C}$. These chips ranged in their electrical characteristics. modes of control. packaging options, and applications. The experimental procedures along with the experimental data obtained on the investigated chips are presented and discussed.

\section{Space Power And Advances In DC/DC Converters}

Most aerospace power management systems are DCbased and thus require DC/DC power converters that will operate over a wide input voltage range to produce an output voltage between $1.5 \mathrm{~V}$ to $15 \mathrm{~V}$ at various power levels.

Recently, there has been a tremendous progress in the design of high power density DC/DC converters. Converters that operate at power densities of $50 \%$ or higher than the available standard conventional converter designs have been developed. This increase in power density is achieved using new designs, advanced devices and components, and packaging techniques. For example, the newly developed synchronous rectifier-based DC/DC converter modules with multi-layer thick-film hybrid packaging provide, without the use of a heat sink, more usable output power than the conventional, schottky diode based converters with a heat sink and thick-film single layer packaging. As the demand to achieve high power density of $\mathrm{DC} / \mathrm{DC}$ converters increases, there is a need to provide more integration and, therefore, the role of highly functional PWM control chips will increase.

\section{INTEGRATED CiRCUITS PWM CONTROLLERS}

Electronic control of DC/DC converter power circuits is achieved by modulating the duty ratio (D) of the controlled switch, defined as the ratio of its ON-time to the switching period. Typically, the intent is to keep the output voltage constant, as determined by a DC reference signal in the presence of time-varying sources and loads. The technique of modulating the duration (or width) of the ON-time (or pulses) that is applied to the drive circuit of the controlled switch is called "Pulse Width Modulation" (PWM).

Fig. 1 shows a simple PWM controller circuit that controls the switch operation in a DC/DC converter. A sawtooth signal with a fixed frequency and a fixed amplitude $\left(V_{R}\right)$ is applied to the PWM comparator whose second input is fed from the output of an error amplifier $\left(V_{e}\right)$ that compares a reference voltage to the output voltage $\left(V_{O U T}\right)$. The output of the latch gives the required PWM signal. This control technique is known as the "voltage-mode" PWM control because only the voltage information is used [15].
It is shown that the utilization of both voltage and current feedback adds significant advantage to the stability of closed-loop PWM controllers. One way of adding the current information is to use the switching analog current waveform in place of the sawtooth generator. The analog voltage of the switching current waveform is usually provided with a small current-sense resistor placed in series with the switch. This control technique is called "current-mode" control and is shown in Fig. 2 [15].

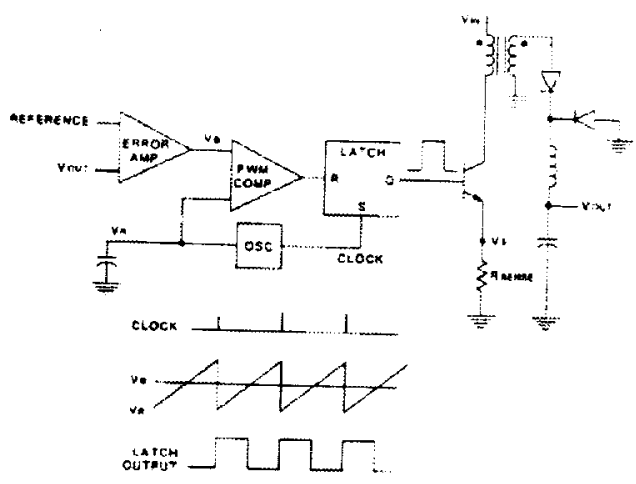

Fig. I Voltage-mode PWM control technique

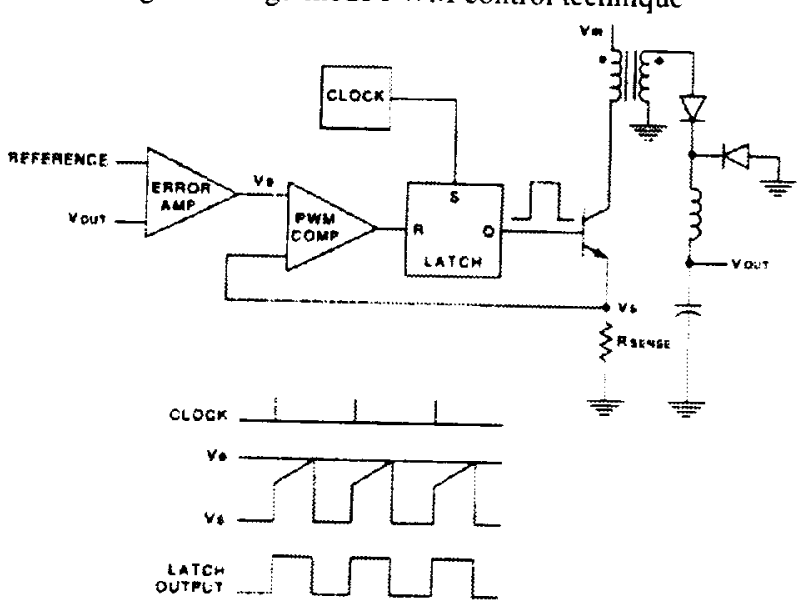

Fig. 2 Current-mode PWM control technique

The fundamental challenge of DC/DC converter design is to simultaneously realize, two difficult objectives: good electrical performance and low cost. A large number of fully integrated PWM circuits, available from a number of manufacturers are designed to meet these objectives. In particular, fixed frequency PWM controllers are by far the devices that are widely used. There have been many ways of implementing fixed frequency PWM control. The basic ingredients of all PWM integrated circuit controllers contain an adjustable clock for setting the oscillator frequency, an output voltage error amplifier, a voltage reference, a signal generator for providing a sawtooth waveform synchronized with the clock, and a comparator to compare the error amplifier output signal with the sawtooth signal. The output signal from the comparator is 
used to drive the controlled switch directly or through a discrete or integrated drive circuit. There has been a large number of PWM integrated circuit manufacturers using different technologies such as all bipolar, BiCMOS or all CMOS which provide all the necessary features to implement fixed frequency control with a minimal external parts count. Moreover. these control chips contain features such as current limiting, over-voltage protection, input under-voltage protection plus primary and auxiliary functions that may improve the performance of the controller. An example of a typical PWM chip is shown in Fig. 3a. Fig. 3b shows the circuit configuration used in testing the performance of the chip. The operating frequency of these chips range from a few $\mathrm{kHz}$ to a few $\mathrm{MHz}$ [15].

\section{LOW TEMPERATURE EXPERIMENTAL SETUP}

A preliminary evaluation of the performance of a number of high-speed PWM control ICs with different packages and ratings, acquired from various manufacturers, was conducted as a function of temperature from $20{ }^{\circ} \mathrm{C}$ to $-190{ }^{\circ} \mathrm{C}$. At a given temperature, the internal voltage reference, and the oscillator and the device modulated outputs were observed. The tests were performed in a Sun Systems environmental chamber utilizing liquid nitrogen as the coolant. A temperature rate of change of $10^{\circ} \mathrm{C} / \mathrm{min}$ was used throughout this work. At every test temperature, the device under test was allowed to soak at that temperature for a period of 30 minutes before any measurements were made. After the last measurement was taken at the lowest temperature, the chips were allowed to stabilize to room temperature and then the measurements were repeated at room temperature to determine the residual effect of the low temperature exposure.

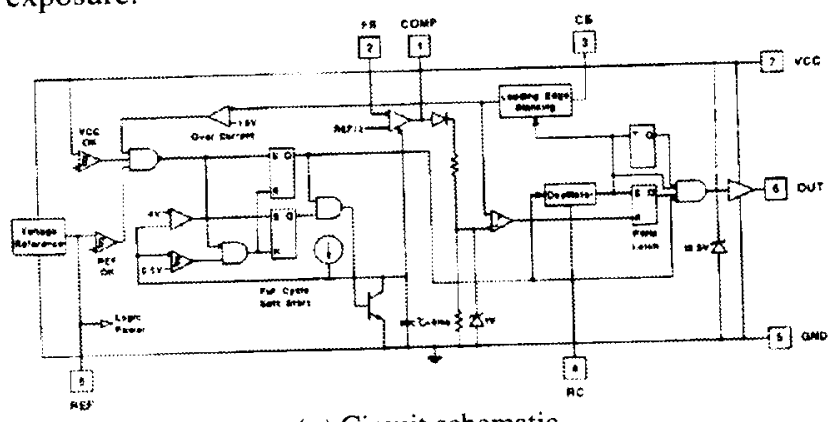

(a) Circuit schematic

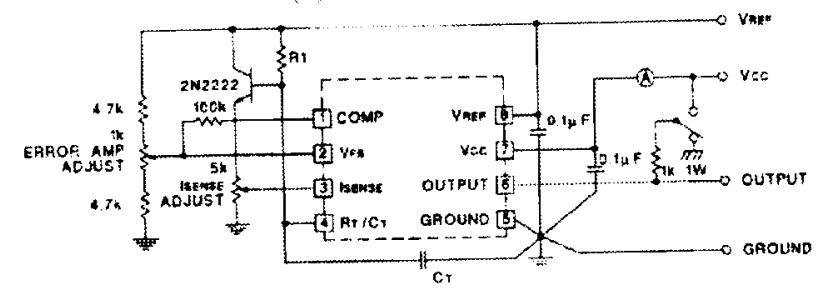

(b) Laboratory test circuit

Fig. 3 PWM current-mode control chip

\section{RESULTS AND DISCUSSIONS}

Four PWM chips were evaluated under various test parameters. Only selected data, which best represents the performance of the devices at low temperature, is presented in this paper. Table 1 gives a comparative list outlining the main features of each of the chips tested. The functionality of each chip at low temperature is evaluated by observing the waveforms of its internal voltage reference, the oscillator frequency and the PWM output. In order to evaluate the chip functionality, a number of external components were required. In the case of chips 1 , 2 and 3 , the tests were performed with only the chip inside the chamber and the rest of the components outside the chamber. Chip 4 , on the other hand, was located on a surface mount evaluation-board, which made separating the components difficult. As a result, the evaluation-board containing chip 4 , as a whole, was tested inside the chamber.

Table 2 shows the variation of the operating frequency for each chip as a function of temperature. It can be seen that chip 1 frequency stayed fairly constant initially but changed considerably as the temperature was lowered below $-80^{\circ} \mathrm{C}$. This chip failed to operate for temperatures below $-140{ }^{\circ} \mathrm{C}$. Chip 2 maintained fairly constant frequency down to its lowest operating temperature of $-180^{\circ} \mathrm{C}$. Similarly, chip 3 maintained fairly constant frequency down to its lowest operating temperature of $-100^{\circ} \mathrm{C}$. The evaluation-board containing chip 4 , on the other hand, displayed considerable change in frequency as the temperature was lowered down to its lowest at $-140^{\circ} \mathrm{C}$. The reason for this could be deviation of some of the external components connected around the chip.

TABLE 1

SUMMARY OF PWM IC FEATURES

\begin{tabular}{|l|c|c|c|c|}
\hline \multicolumn{1}{|c|}{ Chip } & 1 & 2 & 3 & 4 \\
\hline Technology & Bipolar & BiCMOS & Bipolar & BiCMOS \\
\hline Packaging & Dip & Dip & Dip & SOIC \\
\hline $\begin{array}{l}\text { Lowest } \\
\text { Temperature }\end{array}$ & $0^{\circ} \mathrm{C}$ & $-55^{\circ} \mathrm{C}$ & $-40^{\circ} \mathrm{C}$ & $0^{\circ} \mathrm{C}$ \\
\hline $\begin{array}{l}\text { Maximum } \\
\text { Frequency }\end{array}$ & $500 \mathrm{kHz}$ & $1 \mathrm{MHz}$ & $500 \mathrm{kHz}$ & $5 \mathrm{MHz}$ \\
\hline $\begin{array}{l}\text { Duty Cycle } \\
\text { Range }\end{array}$ & $0-100 \%$ & $0-100 \%$ & $0-50 \%$ & $0-100 \%$ \\
\hline PWM Outputs & One & One & Two & Two \\
\hline Control Mode & Current & Current & Voltage & Voltage \\
\hline
\end{tabular}


TABLE 2

VARIATION OF CHIP FREQUENCY WITH TEMPERATURE

\begin{tabular}{|c|c|c|c|c|}
\hline Temp. & Chip 1 & Chip 2 & Chip 3 & Chip 4 \\
\hline $25^{\circ} \mathrm{C}$ & $87 \mathrm{kHz}$ & $67 \mathrm{kHz}$ & $95 \mathrm{kHz}$ & $40 \mathrm{kHz}$ \\
\hline $0^{\circ} \mathrm{C}$ & $89 \mathrm{kHz}$ & $67 \mathrm{kHz}$ & $97 \mathrm{kHz}$ & $39 \mathrm{kHz}$ \\
\hline$-20^{\circ} \mathrm{C}$ & $91 \mathrm{kHz}$ & $67 \mathrm{kHz}$ & $98 \mathrm{kHz}$ & $41 \mathrm{kHz}$ \\
\hline$-40^{\circ} \mathrm{C}$ & $93 \mathrm{kHz}$ & $68 \mathrm{kHz}$ & $98 \mathrm{kHz}$ & $43 \mathrm{kHz}$ \\
\hline$-60^{\circ} \mathrm{C}$ & $94 \mathrm{kHz}$ & $68 \mathrm{kHz}$ & $95 \mathrm{kHz}$ & $47 \mathrm{kHz}$ \\
\hline$-80^{\circ} \mathrm{C}$ & $94 \mathrm{kHz}$ & $68 \mathrm{kHz}$ & $97 \mathrm{kHz}$ & $50 \mathrm{kHz}$ \\
\hline$-100^{\circ} \mathrm{C}$ & $57 \mathrm{kHz}$ & $69 \mathrm{kHz}$ & $98 \mathrm{kHz}$ & $51 \mathrm{kHz}$ \\
\hline$-120^{\circ} \mathrm{C}$ & $54 \mathrm{kHz}$ & $68 \mathrm{kHz}$ & - & $77 \mathrm{kHz}$ \\
\hline$-140^{\circ} \mathrm{C}$ & $51 \mathrm{kHz}$ & $69 \mathrm{kHz}$ & $\ldots$ & $108 \mathrm{kHz}$ \\
\hline$-160^{\circ} \mathrm{C}$ & $\ldots$ & $69 \mathrm{kHz}$ & - & -.-.-. \\
\hline$-180^{\circ} \mathrm{C}$ & --.--- & $70 \mathrm{kHz}$ & - ----- & - - \\
\hline
\end{tabular}

Figures 4 through 7 show the waveforms of the four chips. Figure 4 shows the waveforms for chip 1 at room temperature $\left(25^{\circ} \mathrm{C}\right)$ and at the lowest operating temperature $\left(-140^{\circ} \mathrm{C}\right)$. It can be seen that the reference voltage maintained its value of $5 \mathrm{~V}$ throughout the low temperature test. The frequency of the oscillator and the PWM output dropped significantly at the lower temperatures. Also, multiple switching occurred in the PWM output at the lowest operating temperature.

Figure 5 shows the performance of chip 2 at room temperature and at $-180^{\circ} \mathrm{C}$ (the lowest temperature). This chip is a modification of chip 1 by incorporating BiCMOS technology and a wider temperature operating range, as seen in Table 1. The frequency and duty cycle maintained their values over the temperature range. However, in the PWM output some pulses skipped at the lowest temperature. Comparing the two traces of the PWM output in Figure 5b, the top trace is similar to that at room temperature but some pulses were skipped in the bottom trace.
Figure 6 shows the reference voltage, the two PWM outputs and the oscillator waveform for chip 3. Figure $6 a$ shows the performance at room temperature and Figure $6 \mathrm{~b}$ shows the performance at the lower temperature of $-100^{\circ} \mathrm{C}$. Compared to room temperature, the performance at $-100^{\circ} \mathrm{C}$ shows multiple switching in output $\mathrm{B}$ and also a very noticeable change in the dead time for switching between the two outputs A and B. Except for a few spikes, the reference voltage maintained its value between the two temperature extremes.

The performance of chip 4 at room temperature and at $-140^{\circ} \mathrm{C}$ is shown in Figures $7 \mathrm{a}$ and $7 \mathrm{~b}$, respectively. It can be clearly seen that the reference voltage remained relatively stable but the operating frequency and duty ratio changed considerably. The dead time, however, did not exhibit much change with temperature.

\section{CONCLUSIONS}

An experimental investigation has been performed to evaluate the performance of four high-speed pulse width modulation chips as a function of temperature in the range of $25^{\circ} \mathrm{C}$ to $-190^{\circ} \mathrm{C}$. The chips ranged in their electrical characteristics, modes of control, packaging options, and applications. In general, all of the chips exceeded their manufacturer's low temperature limit. The degree of operational stability of the chips with temperature varied from one device to another. Long term testing at cryogenic temperatures, however, is needed to fully characterize these and other devices for potential use in low temperature applications. 


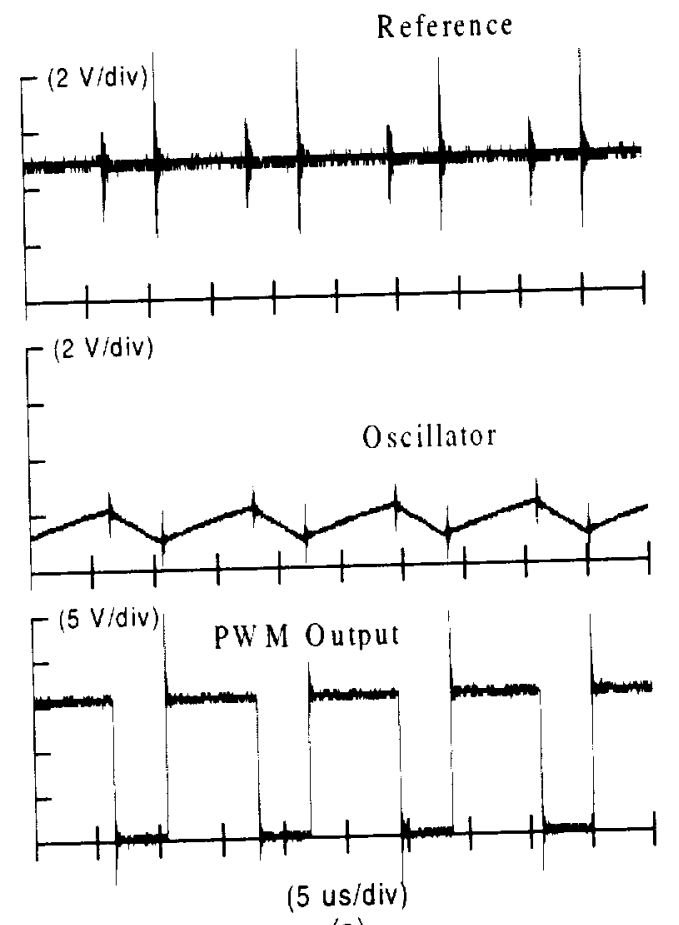

(a)
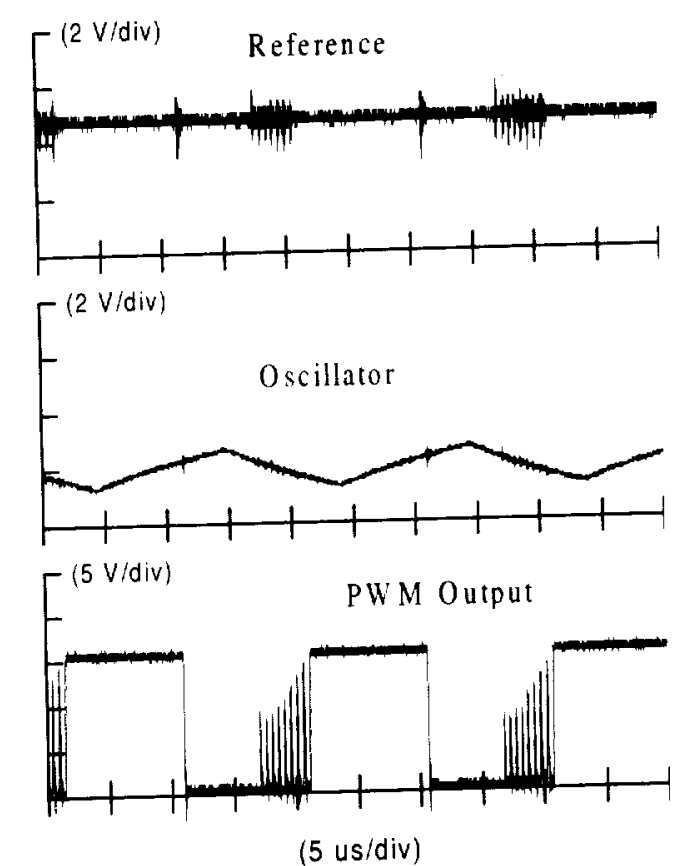

(b)

Fig. 4 Performance of chip 1: (a) at room temperature (b) at low temperature of $-140^{\circ} \mathrm{C}$.
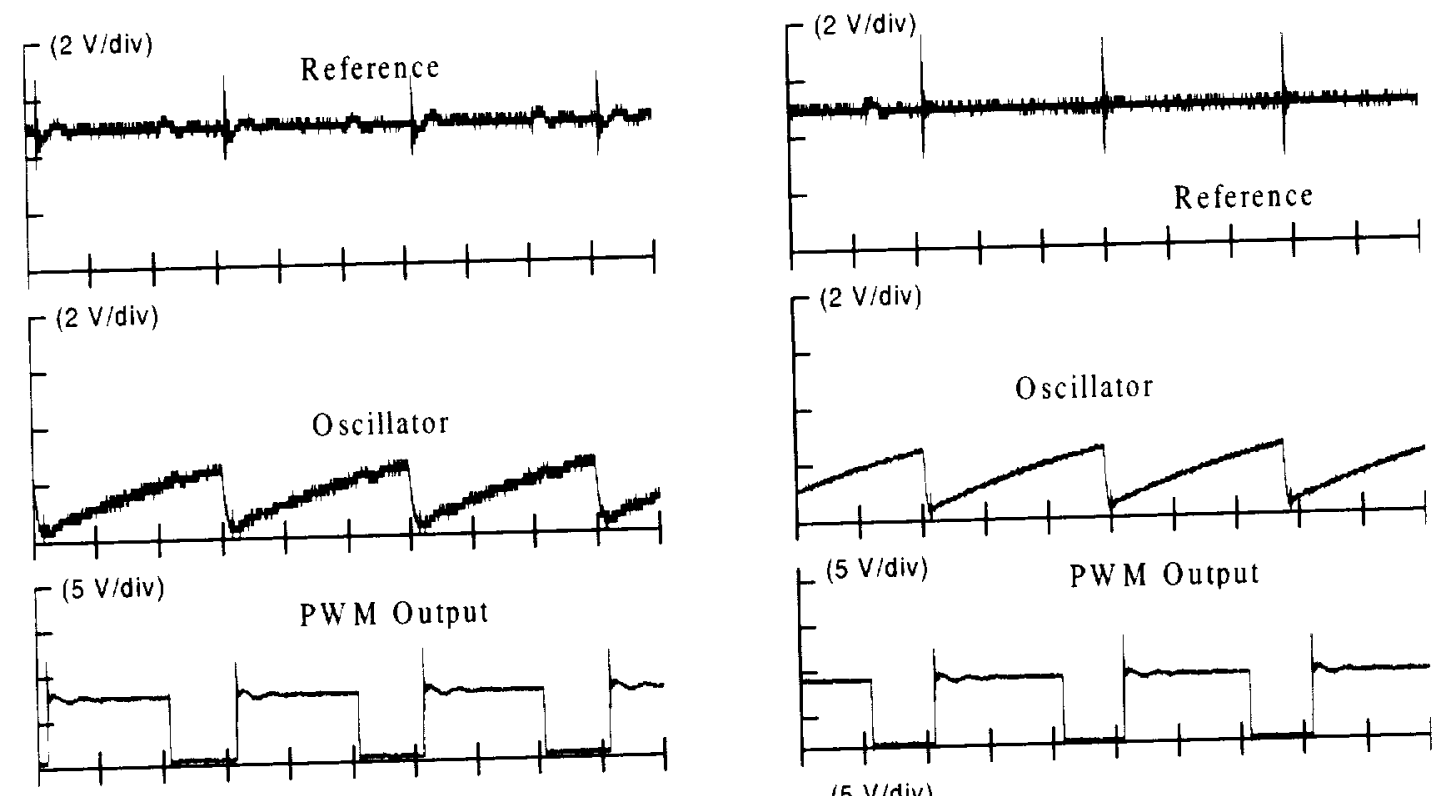

(5 us/div)

(a)

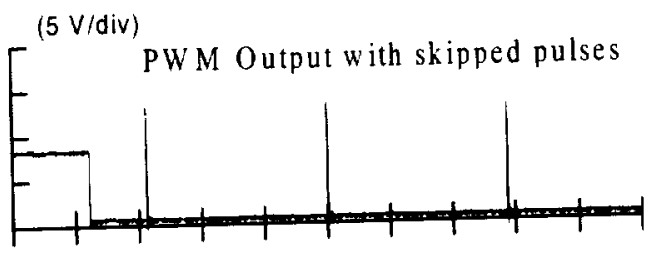

(5 us/div)

(b)

Fig. 5 Performance of chip 2: (a) at room temperature (b) at low temperature of $-180^{\circ} \mathrm{C}$. 


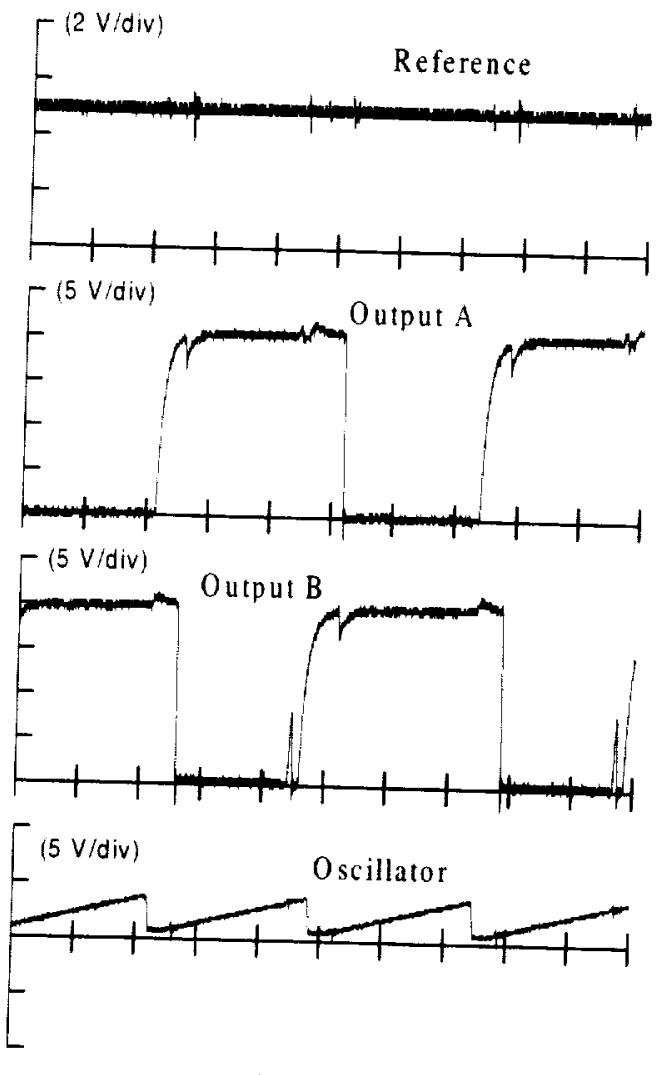

(2 us/div)

(a)
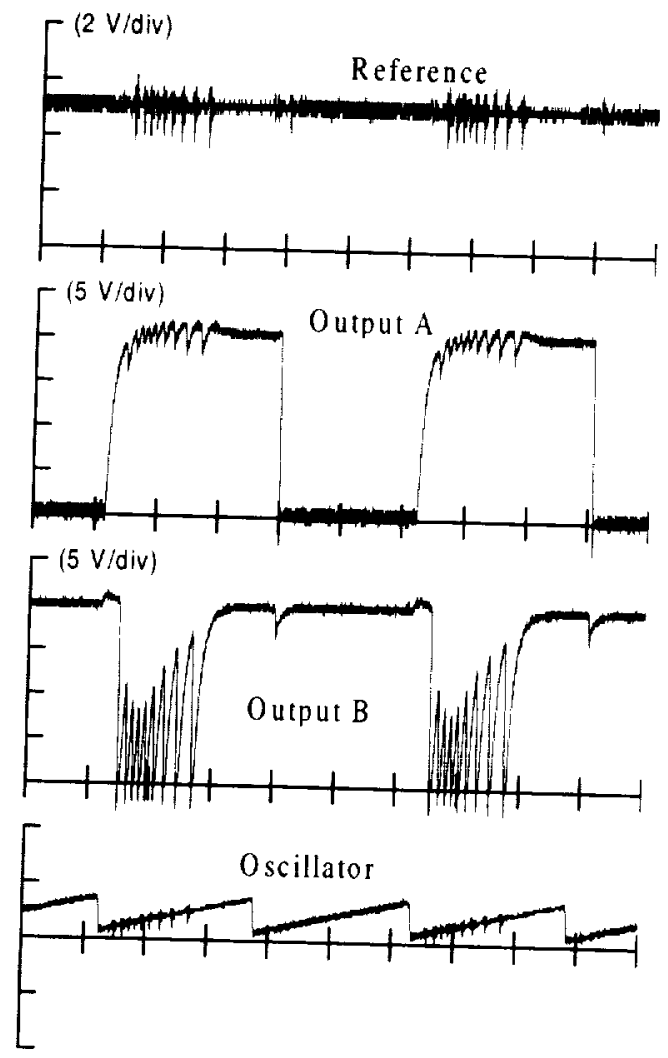

(2 us/div)

(b)

Fig. 6 Performance of chip 3: (a) at room temperature (b) at low temperature of $-100^{\circ} \mathrm{C}$.

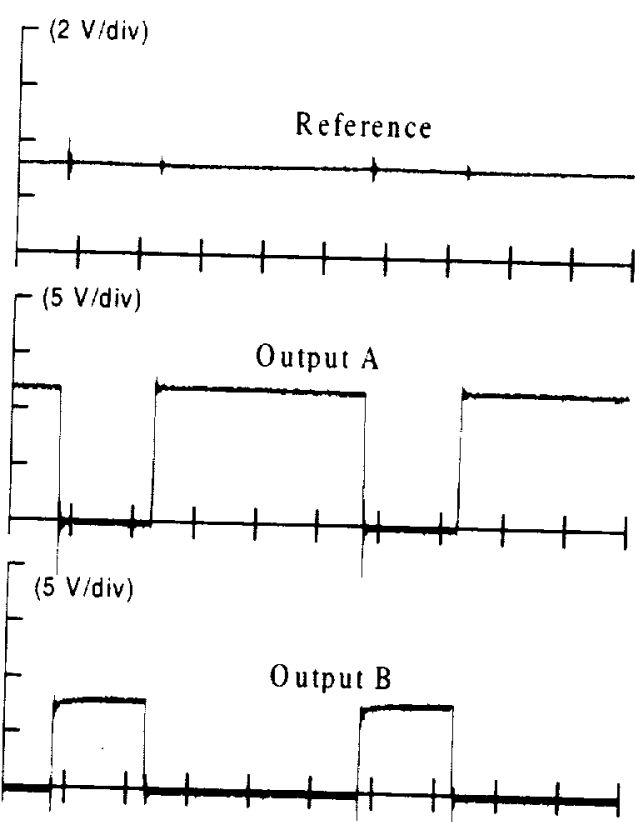

(5 us/div)

(a)
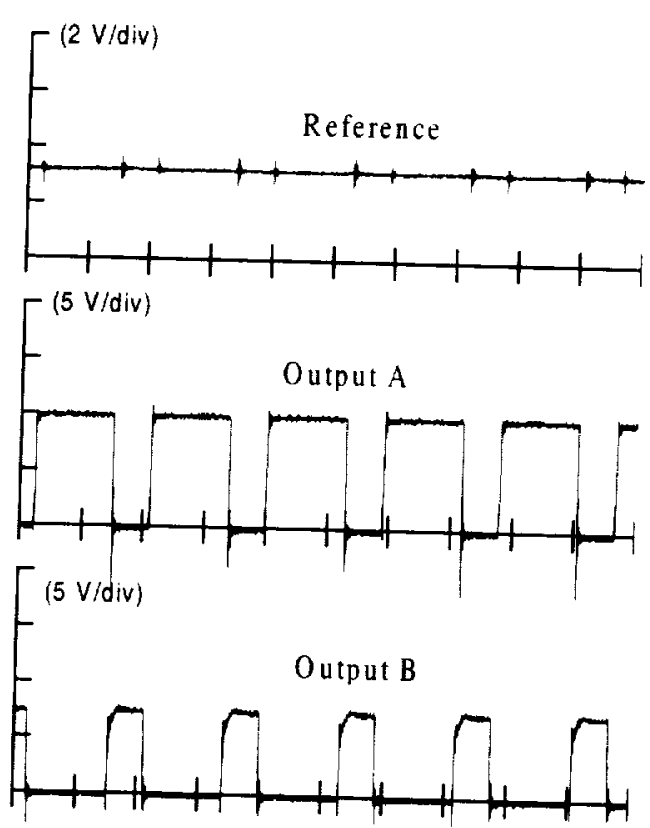

(5 us/div)

(b)

Fig. 7 Performance of chip 4: (a) at room temperature (b) at low temperature of $-140^{\circ} \mathrm{C}$. 


\section{REFERENCES}

1. Gerber. S., Patterson, R., Ray, B. and Stell. C., "Performance of a Spacecraft DC/DC Converter Breadboard Modified for Low Temperature Operation." IECEC 96. Vol.1. 1996. pp. 592-598.

2. Kirschman, R. K. "Low Temperature Electronic Device Operation". 1991 Symp. Electrochemical Society, PV-14

3. Dean. M., Foty, D., Saks, N., Raider, S. and Oleszel, G., "Low Temperature Microelectronics: Opportunities and Challenges," Proc. Symp. Low Temp. Electronic Device Operation, Electrochemical Society, Vol. 91-14, pp. 25-37.

4. Ray, B., Gerber, S.S., Patterson, R.L. and Myers, I.T., "Power Control Electronics for Cryogenic Instrumentation," Advances in Inst. and Control, Vol. 50, Part 1. Int. Soc. for Measurement and Control, 1995. pp. 131-139.

5. Krishman, R.K., "Cold Electronics: an Overview," Cryogenics, Vol. 25. No. 3, 1985, pp. 115-122.

6. Mueller, O., "On-Resistance, Thermal Resistance and Reverse Recovery Time of Power MOSFETs at 77K," Cryogenics, Vol. 29. 1989, pp. 1006-1014.

7. Ray, B., Gerber, S., Patterson. R. and Myers, I., "77K Operation of a Multi-Resonant Power Converter." IEEE PESC'95 Record, Vol. 1, pp. 55-60.

8. Patterson. R.L., Dickman. J.E., Hammoud, A. and Gerber S.S. "Low Temperature Power Electronics Program," NASA EEE Links, Electronic Packaging and Space Parts News, Vol. 4, No. 1, January 1998.
9. Ray, B., Gerber, S.S. and Patterson, R.L., "Low Temperature Performance of a Full-Bridge DC-DC Converter," IECEC '96, Vol. 1, 1996, pp. 553-559.

10. Patterson, R.L., Hammoud, A. and Gerber, S.S., "Evaluation of Capacitors at Cryogenic Temperatures for Space Applications," IEEE International Conference on Electrical Insulation, Washington DC, June 7-10, 1998.

11. Hammoud, A., Gerber. S.S. Patterson. R.L. and MacDonald, T. "Performance of Surface-Mount Ceramic and Solid Tantalum Capacitors for Cryogenic Applications," IEEE Conference on Electrical Insulation and Dielectric Phenomena. Atlanta. GA. Oct. 25-28, 1998.

12. M. Elbuluk, S. Gerber, A. Hammoud and R. Patterson "Characterization of Low Power DC/DC Converter Modules at Cryogenic Temperatures", Proceedings of IEEE 2000 IAS Annual Meeting (IAS'2000), Rome, Italy.

13. M. Elbuluk, S. Gerber, A. Hammoud and R. Patterson, "Efficiency and Regulation of Commercial Low Power DC/DC Converter Modules at Low Temperatures". Proceedings of ," IECEC 2000

14. S. Gerber, A. Hammoud, R. Patterson, M. Elbuluk, "Performance Evaluation of Low Power DC/DC Converter Modules at Cryogenic Temperatures". Proceedings of IEEE 2000 Power Electronic Specialists Conference (PESC'2000), Galway, Ireland.

15. "Power Supply Control Products". Data Book, Texas Instrument, 2000. 


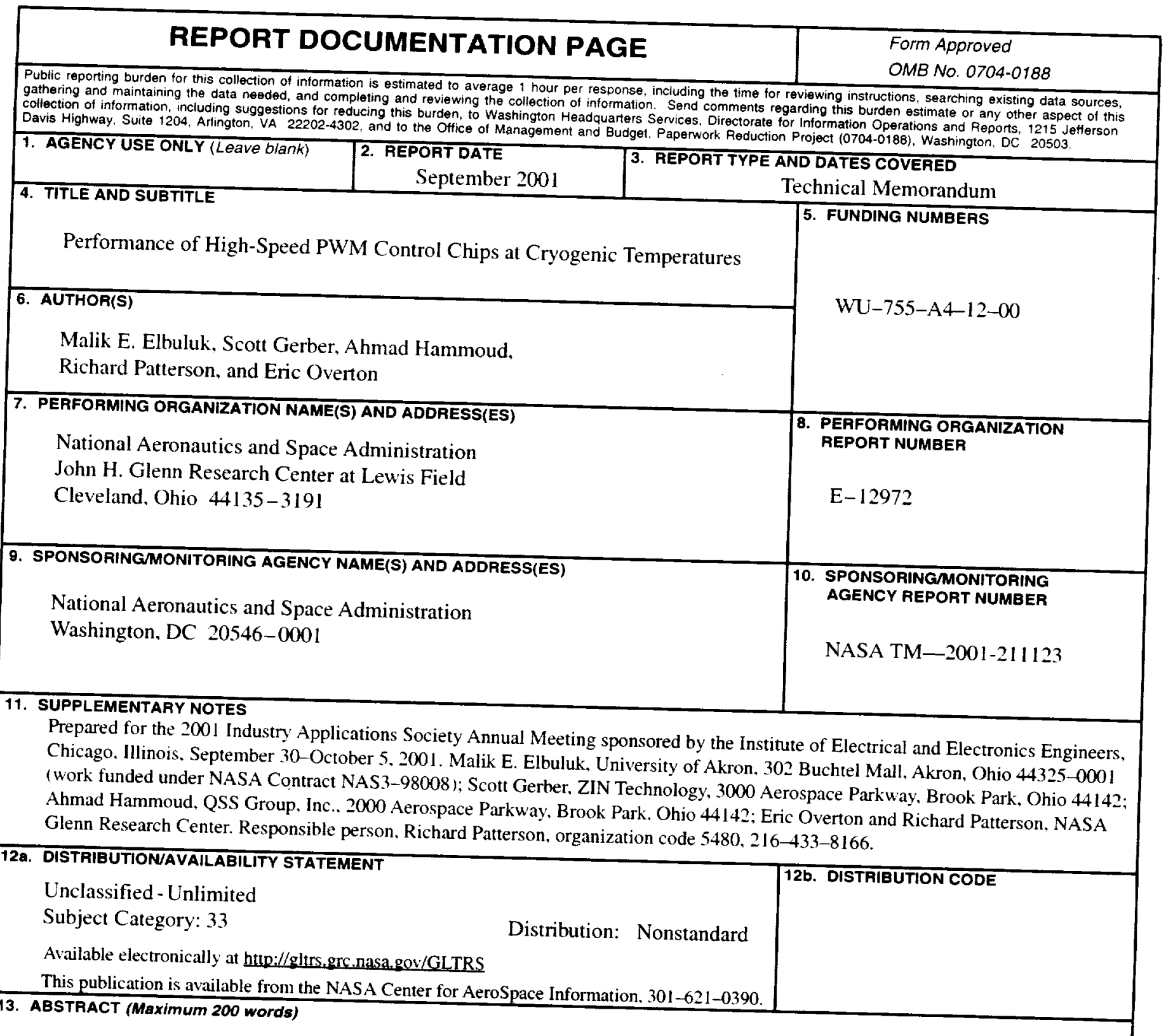

The operation of power electronic systems at cryogenic temperatures is anticipated in many NASA space missions such as planetary exploration and deep space probes. In addition to surviving the space hostile environment, electronics capable of low temperature operation would contribute to improving circuit performance, increasing system efficiency, commercial high-speed Pulse Width costs. As part of the NASA Glenn Low Temperature Electronics Program, several a function of temperature in the range of 25 to $-196^{\circ} \mathrm{C}$ ) chips have been characterized in terms of their performance as teristics, modes of control, packaging options. and applications. The exper These chips ranged in their electrical charactal data obtained on the investigated chips are presented and discuss. The experimental procedures along with the experimen-

14. SUBJECT TERMS

DC/DC converters; PWM chips; Cryogenics; Integrated circuits

15. NUMBER OF PAGES 13

\begin{tabular}{|l|c|c|}
\hline $\begin{array}{c}\text { 17. SECURITY CLASSIFICATION } \\
\text { OF REPORT } \\
\text { Unclassified }\end{array}$ & $\begin{array}{c}\text { 18. SECURITY CLASSIFICATION } \\
\text { OF THIS PAGE } \\
\text { Unclassified }\end{array}$ & $\begin{array}{c}\text { 19. SECURITY CLASSIFICATION } \\
\text { OF ABSTRACT } \\
\text { Unclassified }\end{array}$ \\
\hline NSN $7540-01-280-5500$ &
\end{tabular}



